\title{
Acuerdos, desacuerdos y conflictos sobre el agua. EL juez de agua en el Valle de Quibor, Venezuela
}

Jesús Eduardo Canelón - Profesor agregado del Decanato de Medicina de la Universidad Centroccidental "Lisandro Alvarado", Barquisimeto, Venezuela.Doctor en Psicología Social, Pontifícia Universuidade Católica de São Paulo.

\section{Resumo}

El siguiente artículo discute varios planteamientos realizados por expertos en el tema de los conflictos sobre el agua. Se hace un análisis psicosocial, de la producción de sentidos sobre los conflictos y acuerdos que se relacionan con el agua, en el Valle de Quibor, sobre todo, con el agua de riego y su manejo en época de sequía. Aparece la figura del juez del agua quien, sin tener un poder legal sino un poder que le otorga el ser electo por los usuarios del agua. Se concluye, entre otras cosas, que la mayoría de los conflictos son resueltos rápidamente y de forma pacífica, y que existen leyes y normativas de larga data, así como mecanismos tradicionales, que conllevan el seguimiento de una serie de pasos para intentar resolver los conflictos. Este trabajo fue financiado por la Universidad Centroccidental "Lisandro Alvarado, Barquisimeto, Venezuela.

\begin{abstract}
The following paper discusses various issues raised by several experts on water conflicts. It does a phsyco-social analysis of the production of meanings about agreements and disagreements related to water use in the Valley of Quibor, mainly, about water irrigation and its management in the drought period. Even though the figure of the water judge has an important role in the community; instead of having a legal power he has a community power given by water users. The paper concludes that the majority of conflicts that has taken place within the community are quickly and pacificly resolved and that there exists laws, old regulations and management traditional mechanisms which lead to the monitoring of a series of step that allows the community to resolve conflicts. This work was financially supported by the Universidad Centroccidental "Lisandro Alvarado, Barquisimeto, Venezuela.
\end{abstract}

\section{Palavras-chave}

Manejo de agua, acuerdos, conflictos, juez de agua, Quibor, Venezuela.

\section{Keywords}

Water management, agreements, conflicts, water judge, Quibor, Venezuela. 
Jesús Eduardo Canelón

\section{El Valle y los interlocutores}

El Valle de Quibor presenta condiciones climáticas que lo colocan dentro de lo que se denomina semiárido, con tres meses húmedos y aproximadamente $500 \mathrm{~mm}$ de precipitación anual. Además, el Valle presenta elevaciones que varían entre 820 metros sobre el nivel del mar (msnm) al sur y $600 \mathrm{msnm}$ al norte de la planicie. La temperatura oscila entre una máxima de $31,2^{\circ} \mathrm{C}$ y una mínima de $19,2^{\circ} \mathrm{C}$, con una media anual de $25,3^{\circ} \mathrm{C}$. En el Valle, se cultivan principalmente cebolla, tomate, pimentón, pero existen plantaciones de gran variedad de cultivos que dependen de la época y del productor; entre ellas: lechuga, pepino, cilantro, cebollín, acelga, ajo porro, remolacha y frutas en general. Aparte de las plantaciones, allí también se crían algunas especies de animales (SHYQ, 1998).

Hidrográficamente, el Valle de Quibor forma parte de la cuenca de la quebrada Las Raíces, afluente del río Tocuyo, que pertenece a la cuenca del mar Caribe. Los recursos de agua usados para riego en el Valle provienen del escurrimiento superficial, principalmente de las quebradas Las Raíces y Atarigua, de las aguas subterráneas (actualmente muy explotadas) y de fuentes menores: aguas negras tratadas, drenaje del túnel de trasvase de la represa del río Yacambú, sistema de riego San José de Quibory lavado de los filtros de la planta de tratamiento Ciudad de Barquisimeto, esas dos últimas fuentes reciben agua de la represa Dos Cerritos, localizada en la cuenca alta del río Tocuyo (SHYQ, 1998).

La investigación que sirve de base a este artículo fue realizada en las ciudades de Barquisimeto, Quibor, Sanare y en algunos caseríos ${ }^{2}$ del Municipio Florencio Jiménez como Cuara, Los Ejidos, El Hato, Los Ortices que, junto con otros, constituyen el Valle de Quibor. Forma parte de los estudios que realicé durante los años 2001 al 2004 como parte de mi doctorado en Psicología Social, en la Pontificia Universidade Católica de São Paulo (PUC), Brasil.

Dadas las condiciones agroclimáticas del Valle, la actividad agrícola se realiza exclusivamente bajo riego y se desenvuelve en aproximadamente unas 1.500 unidades de producción de varios tipos: pequeñas, medianas y grandes. Las grandes unidades productivas, superiores a 200 hectáreas son las que aportan los mayores volúmenes de producción a los mercados, debido a que disponen de grandes reservas de agua, equipos para riego, además de otros recursos. Los grandes productores se localizan fundamentalmente en la zona norte del Valle, donde, en las décadas de 1950 y 1960, se inició la actividad agrícola intensiva, conjuntamente con la explotación de las aguas subterráneas. Al sur del Valle se localiza la mayor parte de los propietarios de las pequeñas y medianas unidades de producción, formadas por terrenos

\footnotetext{
${ }^{1}$ Quebrada: río de cauce muy escaso que en verano puede no tener agua

${ }^{2}$ Caseríos: poblados con población rural
} 
heredados de antiguos agricultores de la región que mantenían sus cultivos por el riego hecho a partir del agua disponible en la región, bien sea en las quebradas o por la acumulación en pequeñas y medianas lagunas. Gran parte de la producción agrícola del Valle se realiza mediante la intervención de colonos que son inquilinos de los terrenos. Ellos tienen capital, pero carecen de tierra para producir, o disponen de alguna tierra, pero no cuentan con el agua suficiente para su producción (Dugarte, 2002).

De esta población, entrevisté en sus lugares de trabajo, a los interlocutores que aparecen referidos en el texto y en la tabla de análisis, los cuales son los que mayormente mantienen conflictos por el uso del agua en tiempos de escasez.

\section{A manera de introducción}

En 1995 Ismail Serageldin, en la época vicepresidente del Banco Mundial para el Desarrollo Sustentable del Ambiente, declaró, en una entrevista para el periódico The New York Times, que a pesar de que "muchas de las guerras de este siglo hayan sido motivadas por el petróleo, las guerras del próximo siglo serán generadas por el agua" (Crossette, 1995:A13). Esto, ha generado voces a favor y en contra.

Refiriéndose a esas declaraciones, Shiva (2003) comenta que ya las guerras por el agua están en nuestro cotidiano, sin embargo, difícilmente pueden ser identificadas como guerras por el agua: ellas están relacionadas con peleas religiosas, problemas de tierras u odios históricos, pero, casi nunca con las discusiones por las fuentes de agua.

Tundisi (2003) no concuerda con la afirmación de Shiva, al declarar que "uno de los grandes desafíos del siglo XXI deberá ser la resolución y el acompañamiento de los conflictos internacionales resultantes de la disputa por la disponibilidad de agua" (p.193).

Wolf (1998), en contraposición, señala que a nivel mundial solamente siete pequeñas batallas, tres de ellas sin disparar una sola vez, se produjeron en el siglo pasado por el agua, mientras que fueron firmados 145 tratados entre diversos países para administrar conjuntamente el agua, de un total de 261 cuencas. Según este autor, no se podría decir que no ocurrieron conflictos armados, pero, tales conflictos se dan, generalmente, entre grupos tribales, diversos sectores de usuarios de agua o dentro de un mismo Estado/nación. Algunas de las razones para que eso suceda es que "las guerras por el agua no son ni estratégicamente racionales, ni hidrológicamente efectivas, ni económicamente viables" (p.257). El autor señala, además, que la lección más valorizada sobre las aguas internacionales es el hecho de tratarse de un recurso cuyas características tienden a inducir la cooperación y sólo incitar la violencia en casos excepcionales. Comenta, también, como un ejemplo de lo que ha sucedido con la administración de las aguas compartidas, que la Food and Agriculture Organization (FAO) ha identificado más de 3.600 tratados 
relacionados con el uso de ese tipo de aguas, elaborados entre los anos 805 y 1984. Wolf (1998) también reconoce que la escasez de agua lleva a fuertes presiones políticas en las regiones áridas y semiáridas.

Petrella (2001) argumenta que "el tipo de conflicto más frecuente en estos días tiene que ver con la competencia sobre los usos del agua que, (...) se vuelven mutuamente exclusivos en una estructura caracterizada por la falta de solidaridad y por la escasez creciente" (p.61). Atribuye una gran responsabilidad a las políticas públicas, por la magnitud de tales conflictos:

Cuando un conflicto asume proporciones importantes o críticas, demuestra que la política regional o nacional no fue capaz de desarrollar e implantar una política hídrica integrada, inspirada en la supremacía del interés de todos con relación a un producto o bien común (res publica), y cuyo objetivo fuese estimular la solidaridad entre todos los miembros de una comunidad regional o nacional (PETRELLA, 2001. p. 63).

Batista (1998) parte del principio de que el agua es un recurso escaso y valioso para las comunidades campesinas, además de ser la base de las relaciones sociales, las cuales pueden ser conflictivas o cooperativas. Según el autor, la suposición de que la gestión del agua en sistemas de riego es siempre conflictiva es discutible, aunque considera como cierto que es común la ocurrencia de tensiones y disputas que pueden agravarse. Señala, también, que hay mecanismos y procedimientos, formales o informales, para evitar que tales conflictos aparezcan o para mantenerlos bajo control - generando los menores daños posibles - o para que sean resueltos en su fase inicial. Según este autor, son dos las causas principales de los conflictos producidos por el agua: la escasez, que "no provoca conflictos, pero que es una circunstancia importante, al aumentar la competencia interna por el recurso hídrico" (Batista, 1998, p. 5), y la desigualdad en su acceso, pues, "en los sistemas de riego existe la tendencia de relacionar el problema del acceso al agua a las desigualdades individuales y colectivas (...) en un contexto donde el agua sea escasa" (p. 5).

Este autor clasifica los conflictos por el agua y los divide en: horizontales o verticales e internos o externos. Por una parte, los conflictos horizontales ocurren entre semejantes, personas que pertenecen a un mismo "grupo social", mientras que los verticales se desencadenan entre grupos que se encuentran en distintos niveles en lo que se refiere al acceso y/o control de su gestión, lo que puede ser entendido como manifestaciones de la lucha de clases por el agua. Por otra parte, los internos son aquellos que se desencadenan entre los diversos actores de un sistema de riego, y los externos son conflictos en los que aparecen involucrados una comunidad y algún elemento externo (Batista, 1998).

Tomando en cuenta dicha clasificación puedo decir que en el Valle de Quibor, la mayoría de los conflictos narrados es de tipo interno horizontal o 
externo vertical. En este primer caso, se trata de problemas entre usuarios de una misma fuente de agua, con una situación social parecida, como por ejemplo, los conflictos por el establecimiento y cumplimiento de turnos de agua en las diversas fuentes que analicé durante mi estudio. En el segundo, se trata de usuarios que se encuentran aguas arriba y aguas abajo en un mismo sistema de riego, como en el caso de la quebrada Atarigua, y los desentendimientos entre los agricultores de Sanare y Quibor ${ }^{3}$.

Wateau (2000), en un trabajo de tipo etnográfico sobre los conflictos por el agua de riego en Melgaço, en la zona noroeste de Portugal, donde procuró "investigar la lógica que preside la construcción del orden social en Melgaço, a través de la observación de una actividad técnica agrícola, el riego, que moviliza a una buena parte de la población durante el verano" (p. 29), no concuerda con la premisa de algunos economistas de que la escasez de agua sea motivo suficiente de peleas por el agua. La autora señala que en esa región, aún no teniendo una escasez de agua muy pronunciada, con relación a otras regiones de ese país, esa supuesta escasez es utilizada como pretexto para generar conflictos en el verano todos los años. Eso hizo que ella procurase otras explicaciones para justificar tales conflictos, y no simplemente la escasez de agua.

\begin{abstract}
... en Melgaço "en cuyas cumbres montañosas caen hasta 3.300 Mm. de agua por año y donde las innumerables nacientes brotan de todos lados“, los campesinos se esforzaban todos los años por convencerme de ese argumento explicativo de la escasez, por que les permitía, inteligentemente, legitimar una buena parte de los robos de agua practicados en el Verano, siendo esos los principales causantes de conflictos, en una incontestable forma de afirmación (WATEAU, 2000. p.22).
\end{abstract}

Para la autora, los conflictos en esa región tienen que ver con la importancia que los campesinos le atribuyen al agua, lo que revela la existencia de tensiones permanentes entre los beneficiarios de agua, llevando a creer que, "se el agua de riego es un asunto que motiva a toda la población, es porque sirve de soporte a otras cuestiones más profundas, sociológicas y de identidad" (Wateau, 2000, p. 22). En su estudio, comprobó que todas las personas en Melgaço están más o menos ligadas entre sí por medio del agua de riego y aduce que "el agua es un lazo conflictivo (...), pero también un lazo que aproxima a las personas" (p. 141).

Se puede considerar, entonces, que la posibilidad de que el agua sea generadora de conflictos es un tema que ha sido abordado a partir de varias perspectivas y por diversos autores, algunos de ellos consideran que la escasez y la distribución del agua son por naturaleza generadoras de conflictos, y

\footnotetext{
${ }^{3}$ Dos pueblos que son capitales de los municipios aledaños con usuarios de la quebrada Atarigua, uno en la aprte alta (sanare) y el otro en el valle (Quibor).
} 
otros entienden que es algo común, además de ser fuente para negociaciones, acuerdos y posibles conflictos excepcionales.

En este estudio utilizo la noción de interfase para analizar y comprender los sentidos atribuidos a los conflictos por las personas involucradas en la gestión del agua de riego en el Valle, ya que considero, tal como lo señala Long (2001), que es en los encuentros de interfase, entre las diversas personas con participación en el sistema de riego, en cada fuente de agua en particular,

... que se pueden evidenciar los tipos de discontinuidad que existen y sus dinámicas, y los caracteres emergentes de los conflictos e interacciones que aparecen, mostrando como las metas, las percepciones, los valores, los intereses y las relaciones de las personas son reforzados o reformados por esos procesos (LONG, 2001. p. 191).

Para la realización de este trabajo tomé como base la perspectiva construcionista social y hago uso de dos nociones que son afines con esa perspectiva: análisis de interfase centrada en el actor (Long, 2001) y prácticas discursivas y producción de sentidos (Spink, M.J., 1999). Con base en esas nociones, analizo, a partir de las conversaciones de los jueces de agua, agricultores, funcionarios y técnicos de instituciones y empresas estadales, de las observaciones en el lugar y de los documentos de dominio público, los conflictos que aparecieron durante la construcción del estudio en cinco fuentes de agua disponibles en el Valle.

\section{Los conflictos en la distribución de las aguas en el Valle. Conversando con los actores.}

Seguidamente presento el análisis de algunos de los conflictos que me relataron sobre la gestión del agua de riego en el Valle de Quibor.

A pesar de que los conflictos con relación al agua de riego no formaron parte de los elementos que serían abordados con detalle en el inicio de este trabajo, fue a partir de las conversaciones con los interlocutores que me quedó claro que la distribución del agua en el Valle ha generado y continúa generando discusiones, peleas, acuerdos y desacuerdos, mostrándose como una cuestión fundamental para los agricultores de la región en la gestión del recurso. Decidí entonces prestar un poco más de atención en parte de esos conflictos que aparecieron, y detallar el último conflicto del que tomé conocimiento referente a la distribución del agua que fluye por los bucos y canales del Valle, producto de la limpieza de los filtros de la antigua planta de tratamiento Ciudad de Barquisimeto, y que ha movilizado a varios actores de la región en la búsqueda de una solución a los problemas que esto ha generado. A continuación abordo esos conflictos a partir de aproximaciones sucesivas, en la medida que tuve conocimiento sobre ellos. 
Como una primera aproximación y para visualizar quién es nombrado por los actores cuando se habla de conflictos por el agua en el Valle, a partir de las conversaciones con algunos de estos actores construí una tabla (tabla 1) para intentar identificar quién aparece asociado cuando se conversa sobre discusiones, peleas, negociaciones, acuerdos o soluciones acerca de la distribución de agua o de la intervención de personas no reconocidas como usuarios, en una determinada fuente.

Tabla 1: Los conflictos por el uso del agua.

\begin{tabular}{|c|c|c|c|c|c|c|c|c|c|c|c|}
\hline \begin{tabular}{|c} 
ACTORES \\
\end{tabular} & & & & & & & & & & & \\
\hline QU IER ES REFERIDO & All & DI & Is & AR & EL & ES & SI & TE & AE & FR & $\mathbf{J E}$ \\
\hline Los de Abajo (Quibor) & & & $\mathrm{x}$ & $\mathrm{x}$ & & & $\mathrm{x}$ & & $\mathrm{x}$ & $\mathrm{x}$ & $\mathrm{x}$ \\
\hline Alcalcía de Jiménez & $\mathrm{x}$ & & & $\mathrm{x}$ & & & & & & $\mathrm{x}$ & \\
\hline Blcalcía de $S_{A 0} \Delta r e$ & & & & & & & & & & $\mathrm{x}$ & \\
\hline Autoridades & & & & $\mathrm{x}$ & & & & & & & \\
\hline FE (juez de agua) & & & & $\mathrm{x}$ & & & & & & & \\
\hline Los de arriba (SAD $\Delta r e)$ & & & $\mathrm{x}$ & $\mathrm{x}$ & & & $\mathrm{x}$ & & $\mathrm{x}$ & $\mathrm{x}$ & $\mathrm{x}$ \\
\hline Dueñ os de la hacien da las Galiss & & & & $\mathrm{x}$ & & & & & & & \\
\hline El alcalde & & & & $\mathrm{x}$ & & $\mathrm{x}$ & & & & & \\
\hline Junta (Aproagro) & & & & $\mathrm{x}$ & & & & & & & \\
\hline Mi compadre PL (Ministerio del Bmbiente $S_{\Delta D A r e}$ ) & & & & $\mathrm{x}$ & & & & & & & \\
\hline Guarcia Nacion al & $\mathrm{x}$ & $\mathrm{x}$ & $\mathrm{x}$ & $\mathrm{x}$ & & $\mathrm{x}$ & & & & $\mathrm{x}$ & \\
\hline Minizterio del Ambiente & & & & $\mathrm{x}$ & & & & & & $\mathrm{x}$ & $\mathrm{x}$ \\
\hline CU (juez de agua) & & & & $\mathrm{x}$ & & & & & & & \\
\hline HC (azociación) & & & & $\mathrm{x}$ & & & & & & & \\
\hline TT (agricultor) & $\mathrm{x}$ & & & & & & & & & & \\
\hline H (agricultor que tom aba el agu a con bombas) & $\mathrm{x}$ & & & & & & & & & & \\
\hline $\mathrm{P}$ (agricultor) & $\mathrm{x}$ & & & & & & & & & & \\
\hline MG (agricultor) & $\mathrm{x}$ & & & & & & & & & & \\
\hline Gente de Claimare & $\mathrm{x}$ & & & & & & & & & & \\
\hline DO (juez de água) & $\mathrm{x}$ & & & & & & & & & & \\
\hline SM (agricultor) & $\mathrm{x}$ & & & & & & & & & & \\
\hline Ellos (los agricultores) & & $\mathrm{x}$ & $\mathrm{x}$ & & & & & & & & \\
\hline los 'bomberos' (usan bombas) & & $\mathrm{x}$ & & & & & & & & $\mathrm{x}$ & \\
\hline Junta administr ador a del agu a del túnel & & $\mathrm{x}$ & & & & & & & & & \\
\hline Los cquetienen giembras & & $\mathrm{x}$ & & & & & & & & & \\
\hline In $0 \Omega /$ Hidrolara & & & & & $\mathrm{x}$ & $\mathrm{x}$ & & $\mathrm{x}$ & & & \\
\hline Gobierno del Estado & & & & & $\mathrm{x}$ & & & & & & \\
\hline 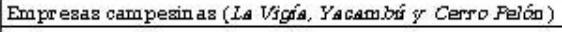 & & & & & $\mathrm{x}$ & & & & & & \\
\hline A.P (agricultor, su hermano) & & & & & & & $\mathrm{x}$ & & & & \\
\hline Los peritos otécnicos & & & $\mathrm{x}$ & & & & & $\mathrm{x}$ & & & \\
\hline Folicía municipal (Com an dante) & & & $\mathrm{x}$ & & & & & & & & \\
\hline Extr actor es de aren a del lecho de la cqu ebr ada Atarigrs $A$ & & & $\mathrm{x}$ & & & & & & & & \\
\hline Grandes prochuctor es (ET e EG) & & & & & & & & & & $\mathrm{x}$ & \\
\hline Militares corruptos & & & & & & & & & & $\mathrm{x}$ & \\
\hline Juez de agua de Atarjgara & & & & & & & & & & $\mathrm{x}$ & \\
\hline Sectores que hacen denuncias & & & & & & & & & $\mathrm{x}$ & $\mathrm{x}$ & \\
\hline
\end{tabular}

En la tabla aparece destacados las personas o instituciones que fueron referidas de manera frecuente por los actores, en situaciones de conflicto. Los más nombrados fueron los de abajo (Quibor), los de arriba (Sanare) y la Guardia Nacional. Tanto los agricultores como los funcionarios coincidieron en señalar a esas mismas personas e instituciones al relatar los conflictos acontecidos en el Valle. A pesar de que cada actor habló de los conflictos más cercanos con su cotidiano y sobre la fuente que utiliza, los problemas que sucedieron en la quebrada Atarigua son los que más aparecen en las 
conversaciones de todos ellos, eso porque la quebrada, cuando lleva agua en abundancia, es utilizada como fuente para regar por casi todos los agricultores que participaron en esta investigación. Muchos son los agricultores referidos por dos de los jueces como las personas involucradas en situaciones de conflictos, la mayoría de ellos porque no obedecen las normas, probablemente por el desespero y el miedo que tienen de perder la cosecha, o porque utilizan las bombas para tomar más agua en perjuicio de aquellos que no tienen bombas.

La Guardia Nacional, como representante de la institucionalidad militar en la zona, es siempre referida, de manera unánime, como la responsable por la solución de los conflictos: ella es llamada para poner fin a cualquier problema no resuelto por el diálogo entre las partes. La policía es menos referida como órgano represor, quizá porque ese tipo de conflicto es producto de situaciones generadas por desacuerdos en la distribución del agua, que es una actividad agrícola y relacionada con el ambiente, área de competencia que corresponde por ley a la Guardia Nacional. La Alcaldía del Municipio Jiménez y el Ministerio del Ambiente también aparecen como instituciones no represivas, pero responsables por el establecimiento y mantenimiento de la legalidad de los acuerdos firmados por todos los usuarios de la fuente de agua.

Se destaca, también, la institución regional de administración de las aguas (anteriormente Inos y ahora denominada Hidrolara), que es referida por tres de los agricultores. En este caso, como ya hemos mencionado, ya que la fuente de agua depende de esa institución y la distribución tiene que ser pagada, la negativa o la imposibilidad del pago por parte de la mayoría de los agricultores ha generado varios de los conflictos narrados.

Los jueces o distribuidores, aún siendo los que distribuyen el agua todos los días, no se señalan a sí mismos como involucrados en los conflictos, sin embargo, aparecen en casi todas las discusiones y peleas por el agua, de una manera o de otra, pues, son ellos, en primera instancia, los responsables por intentar resolver los problemas. En consecuencia, el juez participa o generando el conflicto o en su solución. El magistrado puede generar un conflicto al tratar de cumplir con su trabajo, intentando evitar que alguien viole las normas, o tomando una decisión que cause malestar a algún usuario. Por otro lado, también puede ser parte de la solución del problema, al persuadir a los usuarios a no pelear por malos entendidos.

La figura del juez de agua lleva más de 150 años establecida en la región, en documentos de dominio público se constata las obligaciones y los derechos del juez, así como su ámbito de actuación. Hoy en día, el juez es electo por los propios agricultores de la zona cada dos (2) años o según ellos lo decidan. Aunque no tiene poder legal, asume un papel fundamental en la resolución de conflictos por el derecho al uso del agua y usualmente sus decisiones son acatadas por los agricultores y sustentadas por la autoridad regional o nacional, según sea el caso. 
A lo largo de las conversaciones con las personas, el tema de los conflictos siempre fue señalado, motivado por alguna pregunta mía, o porque el actor lo traía para completar su argumentación, en la mayoría de las veces surgió como parte de la historia que no querían que se repitiese. Como una segunda aproximación a esta temática, seleccioné algunos de los trechos de las entrevistas donde fueron relatados conflictos que aparecen asociados con cada fuente de agua, pues cada una de ellas tiene sus especificidades en lo que respecta a la forma de organización, distribución del agua, normativa, a los tipos de conflicto y soluciones, mereciendo ser consideradas de forma independiente, aunque el Valle sea el lugar de todas.

Es necesario decir que el panorama actual del uso del agua de la quebrada Atarigua tiene, por un lado, principalmente, la presencia de los pequeños productores del Valle, dueños de una antigua tradición de uso de dichas aguas y, por el otro lado, a los grandes productores, generalmente de origen canario, cuya localización más reciente, en las montañas, y su más moderna tecnología los coloca en situación ventajosa con relación a los que viven y trabajan en el Valle. Los conflictos se refieren tanto a la participación de varios actores como a la intervención de terceros, personas que no pertenecen a la región que extraen arena en la quebrada para usarla en la construcción, pasando pelos conflictos entre usuarios de la misma zona de cultivo y los que se suceden entre los agricultores de Sanare y del Valle.

Andrés, usuario de las aguas de la quebrada Atarigua, recuerda los tiempos en que los productores del Valle tenían problemas casi todos los días con algunos productores de Sanare por la distribución de agua de la quebrada. Conversa sobre las reuniones que hicieron con ellos, la Guardia Nacional y el Ministerio del Ambiente, y sobre los acuerdos que establecieron, así como sobre las peleas acontecidas antes de los acuerdos, que por poco no acabaron con la muerte de algún productor. Recuerda, también que los agricultores de Sanare utilizaban bombas a motor para extraer el agua y llevarla para las montañas y, de esta forma, disminuir el flujo para aguas abajo, por lo que algunos de los agricultores del Valle, él se excluye, subían por la quebrada rompiendo las bombas, en un eterno conflicto.

Andrés. Sí, después sí hubo problemas, pero no problemas de llegar a esos extremos, tuvimos un problema nosotros una vez con el agua entre Sanare y Quibor, que es cuando el agua se achica, que a nosotros no nos dejaban usar el agua, de aquí, subíamos mucho, tumbábamos las tomas y ellos las volvían a hacer, después se volvió un zaperoco, porque la gente llegaba y le dañaba las bombas, no era Andrés Eloy, Blanco Distrito, era mandado por el Distrito Jiménez, entonces de aquí mandaban la Guardia y le traían las bombas, eso era un problema ya rotundo.

J. ¿Las bombas eran de quienes?

Andrés. De allá, de los agricultores de Sanare. 
Jesús Eduardo Canelón

A pesar de considerar injusto que los agricultores de Sanare les quitaran el agua, no está de acuerdo con las acciones violentas de los agricultores del Valle. Afirma haber temido que las personas de Sanare los mataran en una emboscada, por la localización favorable de estos últimos en la montaña. Agrega que, a pesar de la intervención de la Guardia Nacional, sólo consiguieron tener paz con la creación de una asociación que estableció un acuerdo con el Ministerio, la Guardia y los agricultores de Sanare, asociación de la cual él fue el presidente. A partir de la firma de ese acuerdo quedó determinado que se repartirían el agua por turnos de tres días para Quibory tres para Sanare, mientras el agua fuese poca, en la época de sequía. Según él, desde el acuerdo no ha habido más problema entre ellos.

J. ¿Y ustedes iban de aquí a echarles a perder las bombas? Andrés. No, yo no me incluí porque nunca me ha gustado eso, yo lo mal hecho, si uno no quiere que le hagan una cosa mal hecha no debe hacérselo a los demás, a mí no me gustó nunca eso, pero sí iban muchos de aquí y les dañaban las bombas. J. ¿Era injusto lo que hacían ellos?

Andrés. Claro, ellos nos quitaban el agua injustamente no nos dejaban el agua, pero tampoco había que pagarles de esa manera, había que abrir un consenso, que fue cuando nosotros, yo me metí en eso un tiempo, que yo le estoy hablando en el 88, me metí yo en una Junta que coordinamos, formamos una asociación y yo me metí de cabecilla y les dije, "miren vamos a dialogar con esa gente, vamos a tratar de hacer consenso", les dije yo, "porque no puede ser posible que nosotros vamos a vivir en este tiempo para allá y para acá, lo más probable es que ellos nos vayan a matar a nosotros porque nosotros estamos entre cerros y ellos fácil nos cazan y nos matan”, les dije yo.

J. Ya usted veía la emboscada.

Andrés. Sí, no, era fácil de que nos tendieran una emboscada, bueno, vino la gente, y tomaron consenso, hicimos una reunión aquí, más de 80 productores, formamos la asociación y fuimos y hablamos, en ese entonces estaba un compadre mío que era que el que dirigía el Ministerio del Ambiente aquí en Sanare, yo le planteé el caso y él nos apoyó, hablamos con la Guardia y también nos apoyó, entonces, llamamos a la gente de Sanare, al Ministerio del Ambiente a Barquisimeto y fuimos los de aquí, y, fue duro, al principio fue duro para poder llegar a un consenso con ellos, pero sí, después llegamos a un acuerdo y se quedó, hicimos unos turnos de agua, son tres días para allá y tres días para acá, en lo que el agua se seca, ahora, en lo que hay agua suficiente, no tenemos nosotros ningún problema, pero sí quedó todo coordinado que son tres días para allá y tres días para acá. 
Andrés comenta sobre la situación de paz alcanzada por ellos, dándole mucho crédito por eso al juez de agua actual. Recuerda que siempre existe la persona que se cree más valiente que las otras quitándoles el agua, pero que con la intervención del juez eso ha diminuido. Agrega que se han civilizado, porque acabaron con las peleas. La palabra civilizado es usada por Andrés para explicar los cambios en los comportamientos de los agricultores de Quibor, en un proceso que se puede denominar evolutivo, según él, donde ser civilizado implica no creerse mejor que nadie, no herir o matar a otro por los problemas de agua, o sea, supuestamente el fin de los conflictos.

J. ¿Y hoy en día, todo el mundo le hace caso a él, no hay conflictos? Andrés. No, se acabaron los conflictos, aquí no hay conflictos ahorita sobre el agua, porque él ha puesto eso en orden, al menos tiene carácter y la gente, yo digo para mí que nosotros nos hemos civilizado, porque antes la gente peleaba por el agua, tenía problemas que, no yo te quito un chorro, entonces venían los problemas, o no te la dejo pasar, porque siempre aquí existió eso, anteriormente, que el que era más guapo le quitaba el agua al otro, entonces ahí habían los problemas, tenía que intervenir.

Al preguntarle si recordaba alguna otra pelea por el agua, me informó que muchos años atrás hasta una muerte ocurrió, cuando un hombre macheteó a otro por tratar de ser más vivo que él y querer quitarle su agua.

J. ¿Qué otros problemas usted recuerda que hubo por el agua? Andrés. Bueno, yo sé que ahí hasta muerto han visto, hacen muchos años mataron uno por, porque le quitó el agua al otro y quería ser más vivo y el otro lo vino y lo macheteó.

Isidro, el juez de agua de la quebrada Atarigua, da su versión sobre los conflictos que ocurren en la distribución del agua. Es él quien realiza la mayoría de las interfases entre los productores de Sanare y de Quibor, siendo esas, además, las más problemáticas, porque involucra a agricultores que comparten la quebrada, estando un grupo en la parte de arriba, lo que les da una cierta ventaja, y los otros, en la parte de abajo. En primer lugar, habla sobre el incumplimiento de los turnos establecidos por el Ministerio. Argumenta que la Guardia Nacional trata de controlar un poco los robos y la falta de cumplimento de los turnos. Sin embargo, los agricultores de Sanare, por el hecho de que están quebrada arriba, afirman ser los dueños del agua, aunque las personas del Valle continúan luchando porque lo consideran su derecho. Utiliza la expresión "siempre nos toca algo" para referirse al hecho de que, aunque poca, siempre reciben agua, resignado a que los de arriba "tengan más derecho" que ellos, porque él forma parte del grupo de los que están quebrada abajo. 
Isidro. ...eso es una cuestión que la ha turnado el ambiente, pero eso en veces no se respeta, esa es una de las cuestiones J. ¿O sea que ustedes a veces tienen problemas con el agua porque los de arriba no les paran?

Isidro. Sí los tenemos, vamos a la Guardia y la Guardia medio controla pero no es igual, ellos están arriba, se atienen a eso "nosotros estamos arriba y no podemos perder, el agua es de nosotros", eso era cuando Quibor pertenecía a..., Andrés Eloy pertenecía a Jiménez, era más distinto, pero ahorita no, porque ellos son ya municipio y el agua y que es de ellos, dicen ellos, hasta ahí nosotros, peleamos los que nos toca y siempre nos toca algo.

En las interfases con personas que no son usuarias del agua, pero que extraen arena de la quebrada para venderla en las construcciones de edificios y casas, cuenta que sólo algunos se ponen de acuerdo con él para realizar dicho trabajo. Comenta un episodio en el cual casi tuvo que pelear con varios obreros de la ciudad de Barquisimeto, los cuales afirma que estaban drogados, porque no les gustó que le dijeran lo que tenían que hacer para no perjudicar el paso del agua por la quebrada. Los trabajadores lo invitaron a darse unos golpes, pero él les respondió que no estaba allí para pelear sino para trabajar y organizar la extracción de arena. Sin embargo, menciona que si hubiese tenido un revólver lo hubiera usado. Comenta que tuvo que ir a buscar a la Policía, que los obligó a vaciar los camiones de arena y devolverla a la quebrada. Al final, les dijo que eso había pasado por no haber seguido sus instrucciones y por ello perdieron el trabajo.

Isidro. Hay unos que son muy buenos y otros que se pasan de vivos, como hay gente que, yo el otro día a unos carajos de Barquisimeto, llegaron allí, si he tenido un revólver te digo que lo fuera cargado, palabra chico, les digo "aquí no vayan a acabar con esto, por esto", unos carajos endrogados ahí, andaban como cinco, "ah, vamos pa allí, para que nos echemos", (sonríe nervioso), "yo no ando, yo ando es trabajando, yo no ando peleando", les dije, "los estoy es ubicando para que no, ni ustedes sean molestados ni yo tampoco, los que llevan el agua y tal", entonces tuve que venirme, tuve que buscar a la Policía, después que habían hecho el trabajo completo, llenado los volteos, tuvieron que vaciar la arena otra vez, perdieron el trabajo, "eso pasa por ustedes, por que yo los estoy es ubicando para que hagan su trabajo", les dije, "entonces, ustedes a cuenta de guapos", no, la cosa aquí se ha trabajado más o menos.

Señala que antiguamente surgían más conflictos, y con consecuencias mucho peores. Argumenta no "haber colocado a nadie a pelear", lo que quiere decir que sus decisiones en la distribución del agua no han generado peleas ni discusiones, porque, además, las personas han mejorado su 
comportamiento. Se refiere también, al homicidio de un agricultor por el robo del turno de agua. Isidro se va posicionando y mostrando las diversas arenas de encuentros en las cuales las interfases sociales tienen resultados diversos, entre ellos, la muerte, heridas con armas de fuego o machete, o discusiones agresivas, todos causados, entre otras razones, por la mala distribución del agua.

En el diálogo que mantuve con Isidro aparecen varias cuestiones interesantes sobre los conflictos por el uso del agua. Parte de la idea de que las personas tienen que tener palabra y mantener las decisiones que fueron tomadas. En el conflicto narrado, a partir de mi pregunta sobre se las personas peleaban antiguamente por el agua, comenta que cree que Carlos actuó legalmente cuando mató Antonio (tío de Isidro) con un machete, pues él siempre le quitaba el turno de agua hasta que Carlos se cansó y luego de matarlo colocó el cuerpo, atravesado, en el buco, tiñéndolo de sangre.

Isidro... Hasta hoy no he tenido problema que no he echado a pelear a nadie, porque aquí la gente se han acomodado, aquí lo que hay que tener es palabra.

J. ¿Antes se peleaban?

Isidro. Sí, aquí han matado gente por cuestiones del agua.

J. ¿A quién por ejemplo?

Isidro. Aquí mataron a un carajo que era hasta tío mío, se llamaba Antonio, el papá de Alberto y todos esos carajos, lo mató un señor que él era, por cierto de El Hato era ese carajo, Carlos, pero te digo, él lo mató legalmente porque el hombre se la tenía aplicada, él tenía su, le daban su turno a él y el hombre, el otro se burlaba de él, se la quitaba y el hombre se obstinó, lo mató, lo mató en el buco.

Isidro cuenta otro conflicto por el agua cuando Amado (que había asesinado a Mario) apuñaló a Cristiano por problemas de agua, y él no se explica como no hubo consecuencias fatales. Ambas personas envueltas en esa pelea ya murieron.

Isidro... en El Molino hubo otro carajo, Cristiano, los dos están muertos ya, un tipo que lo mató un carajo de Playa Bonita, que mató a Mario, en esa curvita que está jodida ahí, ese lo mató, cómo se llama él, Amado, debe ser ese carajo, ese carajo macheteó, por un agua también a Cristiano, le cruzó el machete, yo no sé como no lo mató.

Según Isidro el último conflicto sucedió hace 15 años. Fue cuando Luciano y Pedro pelearan por un agua mal distribuida, pues, Cirilo, el distribuidor de agua de la quebrada Atarigua, le dio el turno a Luciano, y Hernán, el encargado, le dio el mismo turno a Pedro, que, por su vez, le dio un tiro a Luciano, considerando que el turno era suyo. Isidro comenta que Pedro es muy bravo y que aunque el turno no fuera suyo, y que el encargado hubiera 
Jesús Eduardo Canelón

cometido un error, porque Luciano estaba antes en el turno de distribución, no ha debido sacar un revólver y disparar. Para él, los dos hombres no quisieron ceder y por eso comenzaron la pelea.

Isidro. ... y el lío que hubo últimamente ahí, que fue allí por el buco este, Luciano con el Pedro, por cuestiones de un agua, mal repartida porque Cirilo le dio el agua a uno $y$ Hernán se la dio al otro y después no se entendieron ninguno y ellos en la tabla, Luciano está primero y Pedro no quería que se la quitara y le dio un tiro al otro, por agua.

J. ¿Hace cuánto fue eso?

Isidro. No, eso fue hacen ya creo, más de 15 años, fue por eso, por esa agua que se la dieron a los dos, entonces, ninguno se querían dejar y se vinieron a discusiones.

J. ¿Eran dos repartidores?

Isidro. No, había el juez de agua y un repartidor, el juez dijo uno y el repartidor dijo otro, entonces los muchachos se entendieron mal ahí, que no era porque si tú estás primero yo tengo que respetarte que tú estás primero, pero ellos no, porque Pedro se la da de más jodido, peló por el revólver y le dio un tiro al otro.

Tiago, un antiguo agricultor, niega que en su región haya habido personas muertas por peleas por el agua, pero, narra el asesinato de otro agricultor cometido por Amado, que según él, "ya hace tiempo que sucedió", dando a entender que por haber pasado mucho tiempo el asunto ya no tuviera importancia, sin embargo, corrobora la versión del homicidio que Carlos cometió en El Molino, que coincide también con la narrativa de Isidro. Tiago no sabe cual fue el motivo específico de las muertes, pero dice que, con seguridad, la causa de las peleas fue el agua.

Tiago. Que yo sepa, aquí en esta región, aquí no.

J. ¿Y allá arriba en El Molino?

Tiago. Ah, en el Molino sí.

J. Allá si hubo esos problemas?

Tiago. Sí, allá sí, que yo recuerde que hayan matado a alguien por esa agua, fue, un señor Amado. Amado mató a alguien, pero eso hace bastante tiempo. Carlos mató a uno allá en El Molino y se vino para Quibor y después a Carlos, por venganza de ese muerto le mataron a un hijo en El Molino, dos muertos que sepa yo por el problema del agua.

J. ¿Era que a Carlos le quitaban el agua o era él el que le quitaba el agua a los demás?

Tiago. Yo sé que el origen de la rencilla fue el agua, no sé más detalles

J. ¿Ha variado mucho el clima entonces?

Tiago. Sí, ha variado mucho. 
Sergio, nacido en las Islas Canarias, tiene más de 35 años trabajando la tierra en las montañas de Sanare y desde hace más o menos ese tiempo ha estado usando agua de quebrada Atarigua para cultivar fuera de la época de lluvias. Comenta que siempre ocurrieron problemas, y que el primero que comenzó a robar esa agua para regar, utilizando bombas de motor, fue su hermano, que, por las quejas dadas por los agricultores del Valle, era llevado a la Comisaría con sus bombas y todo. Reconoce que las personas del Valle tenían razón, pues, en aquella época esa agua era utilizada para el consumo humano.

\begin{abstract}
Sergio.... siempre ha habido problemas porque siempre usted sabe, antes, anteriormente cuando mi hermano estaba sembrando, que era el único que agarraba una aguita ahí, hasta la Guardia, la Policía de Quibor, porque esto, esto pertenecía a Jiménez y venía, venía la Policía para arriba y se lo llevaba con todo y bomba para abajo de una vez, ajá, una aguita ahí de noche, robándosela, porque ahí si tenía razón Quibor, porque era para tomar, el acueducto era de esta agua.
\end{abstract}

Durante la conversación con Sergio estuve en la compañía de Isidro (juez de agua), que nos presentó y preguntó se podía conversar conmigo sobre el uso del agua de la quebrada en Sanare. Por eso, en algunos trechos de la conversa ambos aparecen haciendo referencia uno del otro, en una supuesta broma llena de dobles sentidos. En párrafo que sigue, por ejemplo, Sergio se posiciona como habitante de Sanare, que define como de mejor cualidad y capacidad productiva que las de los agricultores de Quibor. Diciendo eso, mira a Isidro esperando que esté de acuerdo con él, pero éste mantiene silencio.

Sergio. ... la gente de Sanare, que somos mejores que los de Quibor, no por decirlo yo, ¿ustedes mismos lo dicen, no?

Refiriéndose a los turnos de agua, Sergio señala que algunas veces se cumplen los turnos, pero que otras, las personas de Sanare se ponen muy bravas por la falta de agua y no dejan que corra hacia el Valle de Quibor. Utiliza entonces algunas palabras como se fuesen dichas por Isidro, que está presente, "mire, ya es una maldad quitarle el agua" a las personas de Sanare. Isidro, ante este comentario de Sergio, confirma lo dicho por él y agrega, "ya uno está viendo que no llega". Sergio continúa argumentando diciendo que quitarles esa agua a los agricultores de Sanare es una maldad, por el trabajo y los costos que significa vigilar, extraer y almacenar esa poca agua, y que eso produce mucha rabia.

Sergio. ... Quibor tiene 3 días y 3 noches y a nosotros 3 días y 3 noches.

J. ¿Y eso se cumple? 
Jesús Eduardo Canelón

Sergio. Algunas veces, cuando la gente se pone brava que necesita mucho el agua, que no viene casi agua, no se cumple, vienen los días de Quibor y que va, no la dejan pasar, entonces, va este, y viene siendo el que manda, el juez y dice, "mire, ya es una maldad quitarle el agua”.

Isidro. Ya uno está viendo que no llega.

Sergio. Ya es una maldad, echan, para que llegue un día de agua tienen que echar tres días por ahí y les sale por lo menos por decirte algo 100 ó 200 mil bolívares la bajada de agua, porque tienen que poner gente para que le llegue, en cada buco un tipo, entonces es una maldad que nos hacen a la gente de Sanare que todo se lo va chupando en el trayecto, que con eso nosotros, algo se logra, aquí lo ponemos nosotros, por hora, por días y tal, y tú bombeas 4 horas y yo bombeo 6, pero eso uno ha pasado aquí mucha rabia compañero.

Antes de terminar la conversación, Isidro dijo algo que llamó mucho mi atención, comentó que hoy en día los agricultores de Sanare y Quibor están peleando por las aguas negras de Sanare, pues, hay una laguna de estabilización de aguas servidas que recoge toda el agua de Sanare. Esa laguna, cuando se reboza, las aguas fluyen hacia la quebrada Atarigua, en dirección al Valle, cuando eso sucede, los agricultores utilizan esas aguas para regar sus cultivos, generalmente sin discriminar, el tipo siembra, lo que puede generar problemas de salud pública, en un corto plazo. Esa situación no era conocida por los funcionarios del Ministerio del Ambiente ni del Sistema Hidráulico Yacambú Quibor (responsable por la puesta en marcha de un sistema de riego en el área), pues, cuando hice referencia a ese problema, en las conversaciones, ellos se mostraron sorprendidos de que eso estuviese sucediendo.

Diego, el distribuidor del agua del Portal de Salida del agua del Túnel (otra fuente de agua de la zona), comenta algunas de las estrategias que utiliza para evitar las peleas entre los agricultores. Señala que hace su trabajo intentando distribuir a todos la poca agua disponible y que, se alguno de los productores se enojan. A él no le importa esa situación, pues, el problema es del productor que tendrá que contentarse sólo, porque él no pone a nadie a pelear, ni pelea con nadie.

J. ¿O sea que si a mí me tocó agua el día cinco, me vuelve a tocar agua el día 7 del otro mes?

Diego. Sí cada mes.

J. ¿Y con esas 24 horas lleno una laguna?

Diego. No, no se llena, se siembra poco con la poca agua que agarra, una hectárea, hectárea y media

J. ¿Y la gente no se pone brava?

Diego. Sí se ponen.

$J$ ¿ ¿Y qué hacen, pues?

Diego. ¿Qué van a hacer?, contentarse ellos mismos porque

yo no voy a echar a pelear, ni peleo yo ni pelean ellos, si

134 
se enojan, anoche casualmente voy a darle el agua a la laguna de Víctor y Reinaldo estaba seco aquí, tuve que darle en la noche de anoche y dársela otra vez a Víctor, otra vez, ya mañana es para Ramiro.

$J$. Ah, ¿tuviste que hacer una división?

Diego. Uhum.

J. Te doy a ti un poco y a ti un poco y mañana les vuelvo a dar porque ieste estaba seco?

Diego. Para remediarlos a todos.

Para resolver los problemas y desacuerdos que no consigue solucionar por medio del diálogo, Diego se dirige al puesto de la Guardia Nacional, según me contó. Sin embargo, más adelante me dijo no haber tenido problemas graves con los agricultores, que realizan reuniones para llegar a acuerdos que evitan las peleas, y sobre la necesidad de recorrer a la Guardia Nacional, que éste es el último recurso que utiliza. Comentó, además, que los productores se molestan mucho cuando tienen una siembra y piensan que podrán perderla por falta de agua, ese es el momento de mayor tensión.

J. ¿Y entonces, si tú tienes algún problema a quién acudes? Diego. Ah, a la Guardia, allá.

J. ¿Y ellos te apoyan si hay algún agricultor que te está fregando? Diego. Ah, ok.

J. ¿Nunca has tenido que llamar a la Guardia?

Diego. No, se hacen reuniones para que ellos apliquen las cosas, se le pone la condición a la gente, una semana lo cumplen y después siguen, no, pero no ha habido más bochinche.

J. ¿Tú dirías que está controlada la cosa?

Diego. Por los momentos.

J. ¿Quién se embochincha, cuando no viene el agua y empieza la sequía?

Diego. Los que tienen siembra, es muy bravo, por lo menos tener tres hectáreas sembradas y no tener agua.

El señor Tiago, agricultor jubilado y antiguo usuario del agua del túnel, que ahora es usada por sus hijos, habla siempre del pasado. Para él no existen más conflictos por el agua en la región, pero argumenta que los problemas se presentaban porque alguien plantaba más que otro y, como necesitaba más agua, se consideraba más vivo que los demás, ocasionando constantes peleas.

J. señor Tiago, ¿cuáles eran las dificultades que usted veía para administrar el agua aquí, qué problemas usted ve que eran los más importantes?

Tiago. Los problemas que se presentaban aquí, eran que siempre uno sembraba más que otro y por supuesto, necesitaba más agua y quería siempre más agua que otra persona, y uno que se echa más de vivo que otro, como siempre, como todo pues. 
Jesús Eduardo Canelón

Alcides (distribuidor del agua de los filtros) narra una situación que vivió en la época que distribuía agua de la vieja planta de tratamiento. Un agricultor, establecido en la parte de arriba del lugar y utilizando una bomba eléctrica para llenar su laguna, agarraba más agua de la que debía. Como distribuidor del agua, él no tiene poder para tomar acciones contra aquellos que no cumplen las normas. Por eso, comenta que conversó con el presidente de la asociación para que esta situación no continuara. La solución encontrada fue hacer unas compuertas en la entrada de las tierras del agricultor para controlar el flujo de agua, y el que no pagara la primera vez no debería recibir agua hasta hacer el pago. Sin embargo, según él, el presidente de la asociación (Aproquíbor) no hizo nada y, como no pagaron a la empresa administradora, la entrega y distribución de esa agua, que debía ser pagada, fueron suspendidas.

\begin{abstract}
Alcides. Él la halaba para bombeo y para otra laguna más, entonces, yo hablo con el presidente de la asociación que era Tiago, 'mire Tiago, aquí hay un problema', le dije yo, 'el agua dura 3 y 4 horas para llegar al canal, donde va a salir, en la quebrada pues, y Hugo la larga 4 ó 5 horas, mire si usted no quiere que haya problemas, usted tiene que hablar con Hugo, para hacerle las compuertas o se le hace pagar el agua, porque si seguimos así, que Hugo en la semana te va a agarrar, por lo menos para decir algo, si se suelta el agua todos los días, va a agarrar por lo menos 5 a 10 horas diarias, y entonces, va a acumular mucho billete y no la va a pagar, entonces, la cooperativa, el Inos no le va a vender más agua a la asociación del Hato, le dije. 'Esa es una idea buena, hablar con Hugo, se le pone una compuerta para que se ponga al día', 'porque usted al que le de agua la primera vez, no debe darle la segunda vez hasta que no pague, si usted quiere que esto dure, que sea estable, porque a usted, por lo menos, estando con el Inos al día, uno podía conseguir agua, porque esa agua no es para los agricultores sino para consumo, pero puede haber una solución ahí, un acuerdo, pasarle a una siembra, una cuestión así, verdad?, entonces no me hizo caso, se acumuló mucha plata, entre Plinio, Hugo, Manuel, ah, no nos vendieron más agua.
\end{abstract}

Los problemas en la empresa La Vigía (empresa campesina que utiliza las fuentes de agua) comenzaron cuando la empresa administradora presionó a los agricultores para que pagaran el servicio. Como no pagaron, funcionarios de la empresa colocaron candados en el lugar de distribución de agua. Los agricultores, necesitados del agua para sobrevivir, quebraron los candados y los substituyeron. Los funcionarios quebraron, a su vez estos candados, convirtiéndolo en una rutina diaria.

Elian (socio de la empresa) comenta que fueron muchas las cosechas perdidas por los cortes de agua. Algunos de los cortes duraban un mes, otros hasta dos meses, los agricultores pensaban que el agua era gratis, por eso no 
entendían por qué la empresa les pedía que pagaran. Al preguntarle lo que hacían delante de esta situación, Elian respondió que no hacían nada, sino soportar y hacer los trámites en Barquisimeto para solucionar el problema, por lo que tuvieron que caminar mucho por la ciudad sin conseguir cambiar la situación.

Elian. Ajá, supuestamente que el agua era regalada para los campesinos, para nosotros ahí, pero no sé, no, entonces ahí vinieron los cortes de agua, a veces que por dos meses, por un mes y esas siembras perdidas, porque se perdió mucha siembra, perdimos mucho.

J. ¿Qué hacían ustedes cuando llegaba eso?

Elian. Nada, pues, aguantar la mecha y hacer diligencias para Barquisimeto, nosotros caminamos mucho esa vaina, náguara, eso caminamos demasiado.

Después vino el robo del agua, los candados fueron quebrados para poder regar y mantener los cultivos, hasta el gobierno del estado tuvo que dar una autorización para que pudieran usar el agua.

Elian. No, es que nosotros las últimas veces nos robábamos el agua, teníamos que robarla, reventábamos los candados para poder regar para no perder la siembra, entonces a última hora llegó una orden de que soltáramos el agua y la soltamos.

J. ¿Que la soltaran quienes?

Elian. Nosotros, una orden de la Gobernación que soltáramos esa agua para que no dejáramos perder las siembras que teníamos.

Los principales problemas fueron los que tuvieron con Hidrolara, por el pago del agua. Hoy en día, los agricultores pagan una cantidad establecida por la empresa y reciben el agua, pero, según Elian, ésta no es suficiente para todos.

La problemática de los semilleristas ${ }^{4}$ (otros interlocutores) es muy parecida con la de los usuarios de la empresa campesina. Los productores de semillas colocaron mangueras en la tubería que va desde la represa Dos Cerritos hasta la ciudad de Barquisimeto. Eso producía que la empresa Inos, hoy Hidrolara, ordenara la desconexión de las mangueras, volviendo los productores a conectarlas de nuevo, y así sucesivamente. Finalmente, llegaron a un acuerdo y están pagando por el servicio. En una conversación con Eliseo (presidente de la asociación de semilleristas), nos comentó lo siguiente:

J. ¿De dónde tomaban el agua ustedes, de dónde venía el agua, o de dónde viene, todavía?

\footnotetext{
${ }^{4}$ Los semilleros tienen pequeñas plantaciones de semillas para vender luego las plántulas a otros agricultores.
} 
Jesús Eduardo Canelón

Eliseo. El agua viene de la represa de El Tocuyo.

$J$. ¿Y por dónde pasa, es una tubería?

Eliseo. Sí, una tubería y nosotros tomamos de una

distribución que ellos tienen.

J. ¿Se conectaban ahí?

Eliseo. Exacto.

J. Entonces, ¿venían ellos y les tumbaban las mangueras y después volvían de noche y la volvían a poner?

Eliseo. Exacto, ajá.

J. ¿Ese proceso?

Eliseo. Ese proceso, sí.

Eliseo agrega que, por ahora y desde hace por lo menos 3 a 4 años, no han ocurrido más problemas con el uso y la distribución del agua.

J.¿Han tenido racionamientos últimamente, han tenido algún problema o las cosas son regulares?

Eliseo. No, no, no, ha sido muy normal todo, desde hace como 3 ó 4 años para acá ya no hemos tenido problemas de ninguna clase.

Desde 1987, aproximadamente, según los relatos de los actores, en el Valle las peleas han sido cada vez menos, y las muertes productos de esas peleas son consideradas como cosas del pasado. En el caso de la quebrada Atarigua, por ejemplo, el juez de agua realiza recorridos regularmente para verificar se están siendo cumplidas las normas y los acuerdos entre los grupos situados "quebrada arriba y quebrada abajo", y entre los productores de ambos grupos, en una tentativa de evitar nuevos enfrentamientos con resultados fatales.

\section{A seguir el relato de mi experiencia al acompañar al juez de agua de Atarigua en uno de sus recorridos diarios}

El 28 de enero del 2003, a eso de las 9 de la mañana comenzamos a bajar por la quebrada Atarigua a partir del puente de Bojó, caminamos por rocas y algunos atajos buscando las tomas de aguas ilegales que la gente que vive en esa zona realiza en la quebrada para extraer agua independientemente de su turno de recolección. La técnica que utilizan es colocar unas especies de bucos ${ }^{5}$ artificiales, hechos a veces de cemento, de piedras, de sacos de arena, a veces de estructuras un poco más fijas, para llevar esa agua hasta unas lagunas y después, utilizando bombas bastante potentes, de gasoil, llevarla a otras lagunas superiores, y así sucesivamente con tuberías para mantener agua en la época de sequía para la siembra de papa, que la gente de Sanare cultiva.

Conseguimos una toma ilegal, que el juez se encargó de eliminar y le hicimos un seguimiento al agua para ver adónde iba, el juez supo quién estaba

${ }^{5}$ Canales naturales o artificiales de diversos tamaños que se usan para distribuir el agua de riego. 
robando y también vimos a dos muchachos que estaban en una pequeña siembra usando esa agua, él les informó que eso no se podía hacer porque los turnos de ese día eran de Quibor y les comentó que yo era un funcionario del Ministerio del Ambiente que estaba chequeado con él la situación del agua, pienso que para intimidarlos. Los muchachos no le hicieron mucho caso y continuamos nuestro recorrido. Seguimos bajando por espacio de unas dos horas, y las otras tomas que encontramos no eran ilegales, no había ningún otro problema, pero se notaba que los agricultores de Sanare estaban listos para el turno que les tocaba a partir del jueves, como hoy es martes, y lunes, martes y miércoles le toca a Quibor, los jueves, viernes y sábados le toca a los de Sanare.

Lo que trata de evitar el juez, es que en los días que le toca a Quibor, las personas de Sanare les roben los turnos y los dejen sin agua, porque eso les causa bastante problemas y es una situación constante, tan constante que él debe estar vigilando constantemente el cumplimiento de los turnos. Casi al final del recorrido nos encontramos a cuatro muchachos que, pagados por la gente de Quibor, principalmente de San Antonio de Cuara y por el juez, vigilan para que el agua no sea robada, ni más arriba, de donde nosotros veníamos, ni más abajo.

Luego subimos una colina bien empinada, hasta llegar a la carretera y ahí encontramos a Jorge, un gran productor de papa de la zona, el encuentro me pareció muy interesante pues venía conversando con el juez sobre este agricultor y sobre las lagunas que tiene y el juez me dijo que él era uno de los que metía bomba y cogía el agua cuando no le tocaba. El hombre estaba arriba en la colina, probablemente escuchándonos, y simuló que la chícora que tenía en la mano era una escopeta, y nos apuntó diciendo que nos tenía en la mira para dispararnos si éramos unos invasores, me pareció una broma pesada. A esa broma respondió el juez diciendo que me venía comentando que él era uno de los mayores ladrones de agua de Sanare, a lo que respondió Jorge, sin ningún problema, que este año él no les iba a quitar el agua a los de Quibor, que estuvieran tranquilos porque no pensaba sembrar absolutamente nada, sobre todo papa, porque no tenía ningún interés en perder dinero o en ganar poco dinero, que el riesgo era mucho y las prácticas del gobierno, los bajos precios de los productos y los costos que se estaban disparando hacia el alza, y el problema con los dólares, le hacían pensar que era mejor no invertir este año, no sembrar.

\section{Algunos comentarios finales}

El robo de agua de la quebrada y en las demás fuentes es una de las problemáticas que más aparecen en las narrativas y conversaciones de los jueces y agricultores del Valle y es la situación que ha causado los peores conflictos entre ellos y los productores de Sanare. Por otro lado, parece ser

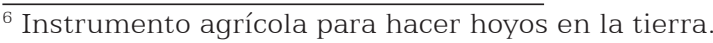


una de las principales razones para que los primeros le paguen al juez para que ejerza el control y la distribución, apoyándose claro, en las normas y reglamentos establecidos.

Los turnos de distribución son elaborados por el Ministerio del Ambiente y se basan en la tradición y en los conocimientos acumulados por los productores sobre la mejor forma de organizarse al respecto. Los grupos de agricultores se comprometen a respetar lo que es decidido cada año, durante la época de sequía.

Los sentidos negociados pueden cambiar, y de hecho cambian a lo largo del tiempo, y las prácticas discursivas de las personas del Valle y de Sanare muestran esas modificaciones, al posicionarse unos frente a los otros y en sus diversas formas de actuar. A pesar de que existan las leyes, las ordenanzas y las normas escritas y mantenidas por tradición, esas personas evidencian, en sus testimonios, formas propias de relacionarse, no establecidas en esos documentos, negociando cotidianamente y organizándose para el manejo del agua de riego.

El juez de agua es el personaje central en ese mundo de la gestión tradicional de agua. Es él quien tiene que negociar todos los días, en primera instancia, como va a ser distribuida el agua entre los agricultores. Tiene también, en las interfases con las autoridades, la potestad de actuar tomando decisiones muchas veces no establecidas en los reglamentos y leyes, por la agencia, el conocimiento y el poder que le es dado, en su condición de elegido por los propios productores, aunque eso no garantiza que represente a todos. Más aún, los jueces o distribuidores tienen que intentar resolver los conflictos que surgen constantemente, aunque en menor cantidad si se compara con épocas pasadas, en el medio de una cuestión tan delicada como es la distribución equitativa del agua en situaciones de escasez.

En el caso del encuentro con los jóvenes supuestos ladrones de agua, la estrategia utilizada por el juez, con la finalidad de intimidarlos, fue invocar la institucionalidad del Ministerio, como entidad coordinadora de los usos del agua en el país, eso porque él no tiene autoridad para actuar unilateralmente, pero puede, por medio de las relaciones que tiene con la Policía y la Guardia Nacional, denunciar los casos de robo para intentar impedir que continúen. Me sentí muy incómodo con lo que pasó, pues no me pareció ético ser utilizado en sus estrategias, sin embargo, me mantuve callado y no hice ningún comentario al respecto. Entendí que siendo yo una persona extraña en el lugar, él utilizó mi presencia para sustentar la autoridad que no tenía en aquel momento.

El episodio con la supuesta escopeta puede ser interpretado como una señal de la desconfianza que existe en la región, y con los cuidados que se tienen delante de personas ajenas al sitio, además de ser una amenaza para quien intente robar alguna cosa del productor. Confieso que mi primera sensación fue de miedo, pues no sabía quién era aquel hombre, además de 
que ya había escuchado sobre muertos y heridos en ese lugar por el robo de agua y yo era un extraño en el lugar. En las relaciones del juez con los otros agricultores sucede ese tipo de situaciones, en las cuales él, según me comentó, en su función de juez, utiliza el diálogo para llegar a acuerdos que permitan la convivencia pacífica entre todos.

Me pareció importante registrar esta conversación, pues ella se muestra cómo se efectúa el desvío (robo) declarado y consciente del agua, la cotidianidad del irrespeto a los turnos de distribución, además de permitir que observara otra situación de interfase y de las relaciones entre los diversos actores (productores, guardias y jueces), y los posicionamientos para argumentar y justificar estas acciones.

Podemos notar, también, las diferencias entre los episodios violentos narrados en las entrevistas y el episodio que viví, en el cual una persona llama a otra de ladrón de agua, sin que se produzca, aparentemente, la menor señal de incomodo ni ninguna reacción violenta, por la supuesta ofensa. Llamar a alguien de ladrón, y que la persona se reconozca como tal y reaccione con calma aparente es completamente diferente a herir o matar a alguien por quitarle el turno de agua o por un malentendido en la distribución de los turnos.

De los conflictos entre pequeños agricultores las situaciones pueden resolverse de varias maneras, generalmente el juez logra encontrar un punto que satisfaga a ambos y considero que son los de más rápida solución, sin embargo, cuando el conflicto es entre un gran productor y un mediano o un pequeño, el gran productor, difícilmente negocia o permite el uso del agua que controla, en estos casos, el gobierno ha sido poco eficaz y complaciente con los que más poseen.

Esta investigación nos permite reflexionar sobre los diferentes tipos de agencia (Long, 2001) de los actores de la región: sus habilidades y capacidades para negociar sus puntos de vista, sus varias maneras de mirar el mundo y dar sentidos a un cotidiano en el cual, la violencia es una de las alternativas posibles, pero que en las negociaciones y acuerdos también son perfectamente viables, como respuesta a esas interfases tan complejas. Del mismo modo, muestra como, a partir de la Psicología Social, podemos entender algunos de los procesos y mecanismos que se establecen en la co-construcción de "mundos de vida" o proyectos personales, a veces coincidentes entre los diversos actores, pero en otros casos contradictorios, en situaciones como la de la gestión del agua de riego en el semiárido venezolano.

${ }^{7}$ Según Long (2001), "Mundos de vida es el término usado por Schutz, para describir los mundos vivenciados (lived-in) y tenidos como obvios (take it for granted) por los actores sociales. Ellos envuelven la orientan la acción práctica que pasa por las intencionalidades y por los valores, y son esencialmente definidos por el actor" (p. 54). 
Jesius Eduardo Canelón

\section{REFERENCIAS}

BATISTA, José. Agua y Conflictos en Sistemas de Riego: Un Análisis Antropológico. In: I Congreso Ibérico sobre Planificación y Gestión de Aguas, 14 al 18 de septiembre. Zaragoza. 1998.

CROSSETTE, Barbara. Severe Water Crisis Ahead for Poorest Nations in Next 2 Decades. The New York Times, p. A13,. August 10. New York. 1995.

DUGARTE, Jesús. El Entorno Físico Natural del Valle de Quibor. Sistema Hidráulico Yacambú-Quíbor, C.A. Gerencia de Desarrollo y Conservación. Barquisimeto. 2002.

LONG, Norman. Development Sociology: Actor Perspectives. Routledge. London/New York. 2001.

PETRELLA, Ricardo. O Manifesto da Água: Argumentos para um contrato mundial. Editora Vozes. Rio de Janeiro. 2001.

Sistema Hidráulico Yacambú-Quíbor, C.A. (SHYQ). Plan Maestro del Valle de Quíbor. Gerencia de Desarrollo y Conservación. Barquisimeto. 1998.

SHIVA, Vandana. Las Guerras del Agua. Privatización, Contaminación y Lucro. Siglo XXI Editores. México. 2003.

SPINK, M.J. (Org). Práticas Discursivas e Produção de Sentidos no Cotidiano: Aproximações Teóricas e Metodológicas. Cortez. São Paulo. 1999.

TUNDISI, José. Água no Século XXI: Enfrentando a Escassez. Rima Editora. São Carlos. Brasil. 2003.

WATEAU, Fabienne. Conflitos e Água de Rega: Ensaio sobre a Organização Social no Vale do Melgaço. Publicações Dom Quixote. Lisboa. 2000.

WOLF, Aaron. Conflict and Cooperation along International Waterways. Water Policy. Vol. 1 n. ${ }^{\circ}$ 2. 1998. 